\title{
STRENGTHENING DEFENCE RESEARCH AS PART OF HIGHER MILITARY EDUCATION FOR FUTURE SECURITY CHALLENGES
}

\author{
Nebojsa NIKOLIC, PhD \\ nebojsa2008_g@yahoo.com \\ Strategic Research Institute \\ University of Defence in Belgrade, Serbia
}

\begin{abstract}
This paper evaluates the potential for defence research to contribute to the long-term development of higher military education. Motivation for the paper emerged from recent organisational changes at the Ministry of Defence by which the Strategic Research Institute (SRI), joined the University of Defence (UoD). Both institutions, SRI and UoD, are obligated and dedicated towards respecting and implementing national strategies, laws and norms related to scientific research and education as well as towards fulfillment of prescribed accreditation standards for academic education and scientific research. The main idea here is to evaluate a scientific research approach conducted by the SRI, through the lens of the guiding principles for development of academic studies which are declared in the national strategy for education development. A few of the questions we tried to answer were: how relevant are the research topics?; who needs research results?; how should the research process be conducted?; and what about the quality of research results? Development of scientific research connections, higher education and practical needs of the military organisation are very important for all three domains, particularly for future security challenges. Military research organisations, along with the higher education component, have to be capable of perceiving future security challenges, conducting scientific research and offering some proposals based on scientific methodology. However, in the selection of the research topics, they have to respect the views, needs and priorities of other organisational entities which are part of the military organisation.
\end{abstract}

Keywords: defence research, military education, security challenges, reform 


\section{Introduction}

Scientific research in the defence sector (Ministry of Defence and Armed Forces), particularly in the domain known as "military sciences" or "defence sciences" is an important issue and a specific endeavour with a multidisciplinary character. Beside their uniqueness, defence research institutions are obligated to respect general rules, norms, laws and strategy related to the business of scientific research. Strategy for scientific and technological development is a document which defines a long term vision, goals and principles (Ministry of Education and Science of the Republic of Serbia 2016). It points out the following main strategic goals: establishing a new efficient system for management in science and innovation; stimulating excellence and relevance of scientific research; obtaining the relevance of science for industry and the economy; improving international cooperation in science and innovation; and supporting investment in science. Similarly to the research field, there are a set of appropriate documents for the field of education. The strategic long-term vision of academic education development points out a few crucial characteristics: quality, relevance, efficiency, internationalisation, mobility, scope and modernisation (Ministry of Education and Science of the Republic of Serbia 2012). There are some obvious similarities in guiding strategic issues in both branches.

Higher military education is a specific kind of education whose main mission is to create (graduate level) and develop (postgraduate levels) professional military officers. The military education system in Serbia, for example, has a mission to create: "the identity of a professional officer - a leader, honourable, loyal, trained and prepared for intellectual and ethical challenges of an officer's vocation in service of the homeland" (Military Academy of the Republic of Serbia 2018). This paper highlights the development efforts undertaken towards implementing the above mentioned principles in the national educational strategy in the context of the military education system and through the aspect of a possible contribution from defence research.

Scientific research is an inherent part of academic education. Scientific activities which are undertaken at academic institutions support the education process in several aspects. They contribute to the long-term development of educators. They offer possibilities for inclusion of students in the field of scientific work 
particularly at master and doctoral levels. They contribute to the development and modernisation of study programmes. Research centres, laboratories and institutes incorporated in the organisational structure of the university have to be the spearhead of scientific research at university. Scientific research is highly creative, very demanding, and an uncertain kind of business, and, being such, stimulates creative thinking and propensity towards the persistent work of students and educators.

Future security challenges and their perception have a dynamic character which varies over time due to the changes in other domains (economic, political, technological, social, etc). This is particularly evident when comparing the new security strategy of the European Union from 2016 (European External Action Service 2016) and the previous one from the year 2003 (European External Action Service 2003). The new one is several times bigger, more concrete, better structured, more pragmatic and action oriented. If we recall the main events related with direct and indirect security violation of the $\mathrm{EU}$ in the period after 2003 it is not unusual:

- the increasing oil price which occurred in June 2008 (more than 140\$),

- the global economic and financial crisis since 2007;

- "the Russia-Georgia war in August 2008;

- the Arab spring; the rise of China;

- changes in the strategic pivoting of the USA towards Asia;

- wars in the Middle East;

- the migrant crisis (several years, multi-directional);

- the crisis in Ukraine;

- terrorist attacks in a number of EU cities;

- the instability in the Balkans;

- Brexit (23 June 2016); etc.

It is interesting that the new security strategy of the European Union was officially presented on 28 June 2016, only a week after the Brexit referendum in the UK (23 June 2016). The uncerainty and complexity of security challenges for small states is even greater because they need to take into account in the influence of global and regional powers (Dengg 2014).

Consideration of relations between future security challenges and the scientific research for military and defence needs, as well as to the higher military education 
process is important and logical. Both processes, scientific research and education, are long-term endeavours. Time frames for scientific projects are measured by years, at least one or two years for smaller projects. The time frame for higher military education is about four years. With these time aspects in mind, it is logical to ask questions about the relevance and actuality of the future research outputs as well as the preparedness and adequacy of the competencies of future military officers.

\section{Aspects of implementation of guiding principles}

The military education system in Serbia is obligated to fulfil all standards of higher education prescribed by the Republic Ministry for higher education and science. One of those general documents is a strategy for education development (Ministry of Education and Science of the Republic of Serbia 2012). Bearing in mind the current state-of-the-art and future desired state, it sets out a long-term vision. The strategy defines several guiding principles which are marked as crucial characteristics for future successful development and they are:

- Quality

- Relevance

- Efficiency

- Internationalisation

- Mobility

- Scope and

- Modernisation.

(Ministry of Education and Science of the Republic of Serbia 2012)

Here, we evaluate a scientific research conducted at the University through the lens of the guiding principles listed above. Some questions which will be tackled are: how relevant are research topics?; who needs research results?; how to conduct the research process; and what about the quality of research results?

Quality. Quality is one of the main characteristics of any human activity. In order to ensure the desired or needed level of quality in academic education and in the field of scientific research, various procedures and criteria are defined in various systems. The criteria for scientific work, that is for quantifying the 
value of a particular scientific result are prescribed by national authorities from the Ministry of Education and Science. Measuring quality or valuation of the quality of scientific research is actually answering the question: "How good is that research?". Various approaches may be applied in order to achieve adequate valuation, comparability and quantification. In Serbia, this task is resolved with one policy document issued by the national authorities under the title: "Rulebook for procedures, valuation and quantification of scientific research results of researchers" (Ministry of Education and Science 2017). This fifty page document defines, classifies and quantifies nine general classes of scientific results. They are: Scientific monographs and chapters of international importance (denotation class: M10); Papers in scientific journals of international importance (denotation class: M20); the book of proceedings from an international scientific conference (denotation: M30); scientific monographs and chapters of national importance (denotation class: M40); papers in scientific journals of national importance (denotation class: M50); the book of proceedings from an national scientific conference (denotation: M60); a doctoral (PhD) thesis (M70); technical solutions (M80); and patents (M90). Each class is further divided into an appropriate number of subclasses with appropriate denotation (for example: M21, M22, M23). Scientific production is arranged and valued according to the mentioned scope of scientific results. Ideally, the majority, if not all, of scientific projects conducted at the University should be generators of a set of different scientific results. Ideally, master and doctoral thesis, as well as promising bachelor's topics, should be incorporated into ongoing research projects at the University. Knowledge of professors and researchers combined with rich experience of military master and doctoral students can produce multidirectional synergetic effects for education, research and the practice side.

Relevance. The main aspect of relevance in this context is related to the importance of the issue of practical needs in the real world. To clarify the aspect of relevance, answering the following question might help, and that question is: "Who needs that research?". In order to be relevant, the research topic should be taken from the practical needs of organisations from the real world. A marketing company or public sector organisation may point out some specific problems which they want to be considered, described and/or solved in an objective, unbiased, effective and comprehensive manner, by experts in the scientific field. In other words, the research topics and consequently scientific results should be relevant and 
purposeful for somebody or something. In order to achieve relevancy, there could be more than one approach. Periodical reports of companies and public service organisations, interviews with chief executives, technical reports on specific issues, "white papers", annual ministerial instructions, quadrennial reports, all could be useful sources of information for selection of research topics related to the questions of interest for real world organisations and companies. Also, direct questioning launched by research organisations towards real world organisations could be an effective way of searching for relevant topics for scientific research. Similar to the previous, there is a technique known as "mapping the needs". In this case, a research organisation officially asks a number of other organisations for their research proposals keeping in mind that every organisation will at least propose those problems which are identified as important and unresolved as well as very relevant for their business. This approach is used at the moment in the Section for Defence Studies of the Strategic Research Institute and the response is very positive.

Efficiency. Efficiency in the context of education is considered through the following indicators: average duration of studies and percentage of the student population who successfully finished studies but without violation of the quality, that is, without reducing the criteria. Efficiency in the field of scientific research, however, isn't concrete enough nor directly in the corresponding strategic documents and rulebooks. There are some indirect indicators which could be perceived as measures of efficiency and these are related to the minimal conditions for achieved scientific results (for example: number and type of published papers) needed for promoting individual researchers into specific scientific titles (research associate, senior research associate, and principal research fellow). However, estimating the efficiency of the research project is more indistinct, particularly when scientific projects are of multi-year duration. Additionally, there is no clear obligation for every individual researcher in the team to have a mandatory level of productivity.

The next aspect of efficiency could be related to the relationship: engaged resources versus achieved results. Money, time, hardware, labs, etc, are all important when evaluating the efficiency of one project. For example, it is not the same when the project team of 6 researchers working 4 years produce a similar level of results as 3 researchers did in 2 years. Both projects could be wrongly evaluated with 
similar marks because of the similar overall results of the projects. However, it is clear that the second project team was much better - they produced a similar output in half the time than the first project team. Additionally, the second team is even better (twice, in the above example), because they did the job in a similar way to the first team but with less researchers. To sum up, the second research team is four times better than the first one $(6 \times 4$ researcher-years, versus, $3 \times 2$ researcher-years).

Project evaluation measures have to take into account those differences and compare in a fair way different individual contributions of the research personnel. The individuality aspect is important because scientific research is highly creative and a very demanding endeavour which often creates some kind of new value. However, high demands in scientific research and the uncertainty factor may be misused sometimes, somewhere by some researchers, as an excuse for their low productivity and a lack of scientific results. As a consequence of that, there are some negative tendencies: organisational self-isolation from the wider academic community; subjective and biased instead of objective and unbiased valuation of individual and group results; ignoring of academic standards, and a rise in the phenomenon known as toxic leadership, which degrades a productive working atmosphere. Because of those risks and challenges it is very important to pay attention to the proper and adequate valuation of research work at academic organisations, particularly those in the public sector which are, by definition, far from other kinds of checking, control or verification on the market.

Internationalisation and mobility. Strategic documents regarding education recognise the importance and role of internationalisation and academic mobility. Internationalisation in education and in the research is a part of the overall national strategic orientation towards the values and standards of the European Union. However, it must be noted that beyond European orientation, there is the almost unavoidable process of globalisation. That phenomenon additionally strengthens the importance of and need for internationalisation. Strategic documents also underline the importance of academic mobility, where it is seen as a tool for better learning and research. Mobility is understood by all sides: students, lecturers, admin staff, and researchers. The University of Defence recently issued a few documents related to this topic: a strategy of internationalisation (UoD 2018a) and a strategy of mobility for students and academic staff (UoD 2018b). Both of 
them are expected to contribute to the following goals: improvement of academic curriculum, enlargement of academic mobility for students and academic staff (professors, researchers and instructors), and advancement of international cooperation with universities, research institutes and partner institutions. Besides the strategies, there are a few additional documents which support implementation of the strategies in practice: Action Plans for implementation of strategies (detailed projections of activities, sub-phases, results, indicators of achievements and subjects responsible for realisation, for the mid-term period 2018-2023); and the Rulebooks, which define precise rules, criteria and procedures needed for planning, support and carrying out activities from the Action Plans. These documents are crucial enablers for successful implementation of strategies for internationalisation and mobility in the academic domain. Their systemic approach will give a powerful momentum towards better education and research at the University of Defence.

Scope. Unlike civilian counterparts, where different dynamics and priorities rule, higher military education and research are very specific. The scope of military education is dominantly rooted in the strategic documents of national security and defence as well as in doctrinal military documents and the vision of longterm development of the military organisation. Simply put, whatever the qualities of the military educational system and research capacities are and whatever the level of attractiveness for joining those institutions, the student and research population cannot be enlarged unlimitedly. Socially, politically and economically such kinds of " militarisation" are unacceptable and unnecessary. However, there are some other aspects. First of all, the selection process for all levels of education, including life-long-learning and recruitment of adequate research personnel, has to be fair, unbiased, with clear criteria and procedures, open for interested individuals, based on objective and measurable norms, equal, and independent of the influence of the superior commanders. Second, in some specific forms of education in the military, such as learning foreign languages during a professional career, effective feedback must be established. This means that those members of the military organisation which attended different educational classes for learning foreign languages in the country and abroad, must be able to use them in professional work and to achieve better results than those who learned foreign languages on their own. This specific phenomenon is particularly interesting for research and educational personnel who are obligated to publish scientific results 
in international scientific journals. Those who were predetermined and privileged to attend language courses in the country and abroad are usually much weaker in that endeavour than those who learn on their own. That paradox is probably enabled by negative selection of personnel (Nikolic 2009) and biased decision making in human resources management. If there was an appropriate feedback control mechanism, such negative phenomena would not exist to such a large extent.

Organisational modernisation. Organisational modernisation of higher military education is challenged permanently, mainly because of new requirements which arise from new and dynamic changes in the field of security and defence. Here, however, we will point out one of connecting points between education and research. Strategic documents underline the importance of the involvement of scientific research activities in the educational process, particularly at the higher levels (master and doctoral studies). How is this achieved? Research personnel should be involved much more in the education process at those levels but with expectations that they will apply and engage their (research) view and so bring new quality and perspective in the education process. However, there is an additional mode and that is the engagement and involvement of professors in the research activities, where the expectation is that they (the professors) enrich and renew their perspectives on the subject. Both directions of education and engagement of research personnel assume clear, fair, intense, dynamic and flexible relationships among educational and research organisations united into the University of Defence. Moreover, both categories of personnel engaged in the education process at the University of Defence, that is professors and researchers, have to have a relevant professional military background. This is about the specificity of professional military career paths, where the so called "educationally-scientific" type of career is at stake. Any learning subject and any kind of research problem related to the military organisation have to be taught and/or investigated by the people who already have relevant professional knowledge and experience of the military organization, which could be gained in one way only: by performing military officers' duties in military units during their early professional life and working in the military. Of course, these specific characteristics need not to be applied to the general educational subjects such as languages, mathematics and so on, while in the field of research work, it is narrower and located mainly in the fields of medical research and engineering. 


\section{Science in the defence education context}

Scientific research in the context of higher military education is performed through a number of projects which are proposed and conducted by the departments of the military educational organisations. Ideally, the doctoral, master and even bachelor thesis should be developed as part of ongoing scientific projects. Also, participation in scientific projects is an effective way to develop the scientific and educational competencies of the professors. Further, conducting scientific research at military educational organisations contributes, particularly in the long-term perspective, to the development and improvement of study programmes as well as to the modernisation of educational resources. A good example of the last aspect is establishing a simulation centre at the Military Academy and involvement of simulation tools and methods in the educational process. The predecessor of that was the intensive use of simulation methods and tools at master and doctoral levels at one particular department of the Military academy (department for military logistics, and in the decades prior to that, it was a department for technical sustainment). In that sense, scientific research is the second central component of academic education. Research centres, laboratories and institutes incorporated in the organisational structure of the University have to be the spearhead of scientific research at the University and a proper place where students are introduced to the latest achievements in any educational and scientific field.

However, implementing beneficiaries of the contribution of science to the education is not an easy task, nor simple endeavour. Large organisations have complex structures and many sub-organisations. With the passage of time, the initial concept of internal cooperation may vanish and sub-organisations tend to conduct their own partial agendas and values, on account of a parent-organisation main agenda. This phenomenon is known as organisational silos and it is an open question for modern business, management and public administration. Scientific institutes and centres which are incorporated in the structures of the University have particular importance. They should be leaders in recognizsing and dealing with contemporary complex practice in defence business by furthering both military education and research (Dalgaard-Nielsen 2017). Due to the complex environment and its dynamic nature, as well as the obligation of the military to 
be prepared for an uncertain future, military education is sometimes perceived as the "cornerstone of a military's capabilities" (Yong-De 2017). Profiling long-term vision in defence business is not an easy task (Stojkovic, Dahl 2007) and a number of management methods should be applied combined (RTO/NATO 2003).

A couple of successful efforts in carrying out research projects with established links between science and practice are (country case Serbia): Strategic Research Institute, an organisation in the University of Defence, which recently finished one externally ordered scientific project called "Propensity to Serve in Military Active Reserve" (Strategic Research Institute, 2016). Extensive empirical research was done in order to obtain rough data for further analysis. One step forward was undertaken and, unlike the similar research in the past, a novel idea was implemented -which enabled electronic fulfillment of the survey by the wider public. Results of the project research were prepared according to scientific standards and launched at scientific conferences and in journals. So, the overall result was twofold: scientific (a set of scientific articles produced) and practical (an external client who initiated the research and suggested the topic got his technical report on the subject). Additional benefits from the project were: recognition of the Institute as a useful organisation of the MoD, as well as the development of the internal research capacities of the Institute through better production of scientific work (efficiency) and improved transparency of results (effectiveness).

The second example is the ongoing project at the Strategic Research Institute, which is known as "Hybrid Warfare - Experiences and Perspective" (Strategic Research Institute, 2017). Similarly to the previous, the research topic was suggested by some external organisational entities of the MoD. Beyond the ordinary project activities and due to the actuality of the topic for the defence and security community, a scientific and expert meeting was organised and held in December 2017 at SRI. Participants came from very different organisations with a broad spectra of research topics and that diversity confirmed the potential for mutual benefits for all three sides: science, education and practice.

Concrete proposal. Research organisations in the public sector sometimes have a problem evaluating their work and performances. Sometimes a project itself is questioned because of its relevancy, that is, a crucial question remains unanswered: "who needs that project?". Sometimes, the quality of scientific results is questioned ("how good are the results?"), particularly when even a minimal 
researcher's productivity is not achieved. In order to contribute towards finding solutions for the above mentioned problems, there is one simple idea. The proposal of a general approach for selection of the research topic, conducting the research process, and the verification and validation of research results may be summarised in a few steps:

- Appropriate selection of a research topic that is, answering the first fundamental question: "who needs that project?" The first step is crucial, particularly for the aspect of relevancy. This is about connecting theory and practice. The main point is searching for a connection between theory (science) and practice. In order to obtain the relevance of research for practical problems, the simplest way is to ask the "practice" side to give a proposal (or a set of proposals) for research. That is, they are expected to formulate a problem (or a set of problems) which they want to be solved by the use of scientific resources. In that way, the relevance aspect is assured in advance: the proposer of the research topic is identified and it is logical to expect that he will be a main user of future scientific results. The importance of connecting research and practice was also recently stressed (Baaustrup, 2017) at one referential conference.

- Conducting a research process. The crucial thing in this phase is the capability of a research organisation to produce a research plan, to find resources needed for the research, to define proper timelines, to prescribe indicators of success, and to motivate, lead, control, support and guide research staff towards successful realisation of a research plan. As mentioned at the beginning, scientific work is a creative activity but also uncertain, and because of that the research path is an oscillatory movement between hits and misses. Due to this character of scientific research processes, scientific organisations as well as individual researchers have to be resilient, flexible, persistent and self-critical in doing their research work.

- Verification and validation of research results answers the second fundamental question: "how good are the results?" produced during research on the project. Publishing research results in scientific journals and the proceedings of scientific conferences is a "modus operandi" in the business of scientific work. In order to be published, an article has to be read and accepted by the journal's editor and peer reviewers. After being published, the paper is exposed to critics and review by a wider readership. So, the paper has to be good enough in order to fulfill scientific standards. Scientific monographs (books) should 
arise from several journal articles and are dedicated to a particular scientific problem or application. Patents, innovations and technical solutions arise directly from scientific research and are directly applicable in the real world. In short, a collection of scientific publications of various types is the main shopwindow of the scientific project conducted at academic institutions. Publishing for international scientific journals has a very important place in evaluating a project's success, as well as in valuing individual contributions of researchers. In practice, however, many problems may arise: unbalanced production of individual researchers, reluctance towards publishing at international scientific events, weak proficiency in foreign languages, limited reading and monitoring of relevant literature (particularly those in foreign languages), poor computer proficiency (particularly among the social scientists), lack of research capabilities (many individuals entered research and academic organisations because of good working conditions and not because of propensity towards creative but demanding scientific work), etc.

\section{Conclusions}

The University of Defence is on its way towards consolidating higher military education and the research function. It started recently with organisational changes which strengthened relations between education and research organisations. One of the next crucial steps is clarifying a long-term vision, values and guiding principles for future work. Incorporated research organisations should bring new quality into education as a premier function of the University of Defence, while at the same time it needs to transform itself in the direction of a better research capacity in order to satisfy relevant needs of the military organisation now and in the future.

In this paper, we discussed relationships between the research and education function at the University of Defence in order to clarify contributions to development of the long-term vision of the system of higher military education. We did that from the perspective of the research organisation which is attached to the University of Defence. In order to achieve synergetic effects from organisational 
unification, we offered some prospective proposals for managing future research projects at the University and strengthening its overall capacity.

Acknowledgements: This work is partially supported by the Ministry of Education and Science of the Republic of Serbia under interdisciplinary Project No.III-47029 ("Cost Effective Selection of New Technologies and Concepts of Defence through Social Reforms and Strategic Orientations of Serbia in the 21st Century").

\section{References}

Baaustrup, P.M., 2017. Military Reality and Military Research - the Difficult Connection Seen from a Danish Perspective. Proceedings of the ISMS-2017 Conference Military Sciences - The Backbone of Military Educational Institutions, Norwegian Defence University, Oslo. [online] Available from: http://www.isofms.org/pagina/ismsconference-2017.html [Accessed 8 Apr 2018].

Dalgaard-Nielsen, A., 2017. Complexity Strategy - Furthering Military Research and Education. Proceedings of the ISMS-2017 Conference Military Sciences - The Backbone of Military Educational Institutions, Norwegian Defence University, Oslo. [online] Available from: http://www.isofms.org/pagina/isms-conference-2017.html [Accessed 8 Apr 2018].

Dengg A., 2014. Hybrid Threats: A Future Threat Scenario and Implications for Small States. Proceedings of the International Society of Military Sciences Annual Conference, ISMS, Vienna, Austria, 21-22.

European External Action Service (EEAS), 2003. A Secure Europe in a Better World European Security Strategy. EEAS, Brussels.

European External Action Service (EEAS), 2016. Shared Vision, Common Action: A Stronger Europe - A Global strategy for the European Union's Foreing and Security Policy, EEAS, Brussels.

Military Academy of the Republic of Serbia, 2018. Our mission. [online] Available from: http://www.va.mod.gov.rs/cms/view.php?id=6583 [Accessed 8 Apr 2018].

Ministry of Education and Science of the Republic of Serbia, 2016. Strategy for scientific and technological development of the Republic of Serbia 2016-2020. [online] Available from: http://aler.rs/files/STRATEGIJA_naucnog_itehnoloskog_razvoja_Republike _ Srbije_za_period_od_2016_do_2020_godine_Istrazivanja_za_inovacije_Sl_gl_RS_ br_25_2016.pdf [Accessed 8 Apr 2018].

Ministry of Education and Science of the Republic of Serbia, 2012. Strategy for education development in the Republic of Serbia up to 2020. 
Ministry of Education and Science of the Republic of Serbia, 2017. Rulebookfor procedures, valuation and quantification of scientific research results of researchers. [online] Available from: http:/www.mpn.gov.rs/wp-content/uploads/2017/03/Pravilnik2017-preciscen-tekst.pdf [Accessed 8 Apr 2018].

Nikolic, N., 2009. Culture of Career Development and Ranking and Selection of Military Officers, Western Balkan Security Observer, No.14, 120-141. [online] Available from: https://www.ceeol.com/search/article-detail?id=24005 [Accessed 12 May 2018].

Paile-Calvo, S., 2016. From European Mobility to Military Interoperability: Exchanging Young Officers, Knowledge and Know-How. Luxembourg: Publication Office of the European Union.

RTO/NATO, 2003. Handbook on Long Term Defence Planning. RTO-TR-069.

Stojkovic, D., Dahl, B.R., 2007. Methodology for long term defence planning. Report FFI-2007/00600, Norwegian Defence Research Establishment (FFI). [online] Available from: http: //www.ffi .no/no/Rapporter/07-00600.pdf [Accessed 8 Apr 2018].

Strategic Research Institute, 2016. Project: Propensity to Serve in Military Active Reserve. [online] Available from: http://www.isi.mod.gov.rs/eng/289/zainteresovanost-zasluzbu-uaktivnoj-rezervi-zavrsen-289 [Accessed 8 Apr 2018].

Strategic Research Institute, 2017. Project: Hybrid Warfare - Experiences and Perspective. [online] Available from: http://www.isi.mod.gov.rs/eng/36/hibridno-ratovanjeiskustva-iperspektive-aktuelan-36 [Accessed 8 Apr 2018].

University of Defence, 2018a. Strategy of internationalization. [online] Available from: http://www.uo.mod.gov.rs/sr/o-univerzitetu/dokumenta-propisi\#.WrY2XNTwZdj [Accessed 8 Apr 2018].

University of Defence, 2018b. Strategy of mobility for students and academic staff. [online] Available from: http://www.uo.mod.gov.rs/sr/o-univerzitetu/dokumenta-propisi\#. WrY2XNTwZdj [Accessed 8 Apr 2018].

University of Defence, 2018c. Action plans for implementation strategy of internationalization. [online] Available from: http://www.uo.mod.gov.rs/sr/ouniverzitetu/dokumenta-propisi\#.WrY2XNTwZdj [Accessed 8 Apr 2018].

Yong-De, A.F., 2017. The Importance of Professional Military Education (PME) in the Changing Context of War. Proceedings of the ISMS-2017 Conference Military Sciences - The Backbone of Military Educational Institutions, Norwegian Defence University, Oslo. [online] Available from: http://www.isofms.org/pagina/isms-conference2017. html [Accessed 8 Apr 2018]. 